\title{
Resposta do meloeiro à fertigação controlada através de íons da solução do solo: Desenvolvimento vegetativo ${ }^{1}$
}

Manoel J. da Silva Júnior², Sergio N. Duarte³, Francisco de A. de 0 liveira $^{3}$, José F. de Medeiros² \& Indalécio Dutra ${ }^{2}$

\begin{abstract}
RESUMO
0 manejo da fertigação é feito mediante o uso de curvas de absorção de nutrientes; entretanto, o monitoramento dos nutrientes na solução do solo surge como técnica promissora. O bjetivou-se estudar a resposta do meloeiro submetido a concentrações controladas de nitrogênio e potássio na solução do solo. Adotaram-se 13 tratamentos dispostos em delineamento inteiramente aleatorizado com 4 repetições. 0 s tratamentos resultaram do manejo controlado das concentrações de nitrogênio e potássio na solução do solo. A cultura foi irrigada por gotejamento e a fertigação realizada somente quando foi necessário. Avaliaram-se: comprimento da haste principal, diâmetro do caule, número de folhas, área foliar, área foliar média e matéria seca e se realizou análise de variância e de regressão com o uso do SAS. Aos 30 dias, as melhores concentrações de nitrogênio e de potássio foram 336 e $84 \mathrm{mg} \mathrm{L}^{-1}$, respectivamente. No final do ciclo a melhor concentração de nitrogênio na solução do solo foi de $336 \mathrm{mg} \mathrm{L}^{-1}$ e a de potássio variou entre 35 e $44 \mathrm{mg} \mathrm{L}^{-1}$.
\end{abstract}

Palavras-chave: Cucumis melo L., concentração iônica, extratores de cápsula porosa, nitrogênio, potássio

\section{Response of melon plants to fertigation controlled by ions of the soil solution: Vegetative development}

\begin{abstract}
Fertigation management is done by the use of the uptake nutrients curves. However, the tracking of the soil solution nutrients concentration appears to be a promising technique. The objective of this work was to study the response of melon plants subjected to controlled concentrations of nitrogen and potassium in the soil solution. 13 treatments were adapted, disposed in fully randomized design with 4 replications. The treatments resulted from the management of controlled concentrations of nitrogen and potassium in the soil solution. The crop was drip irrigated and fertigation was carried out only when necessary. The length of the main stem, stem diameter, leaf number, leaf area, average leaf area and dry matter were evaluated, and analysis of variance and regression using the SAS were performed. At 30 days, the best concentrations of nitrogen and potassium were 336 and $84 \mathrm{mg} \mathrm{L}^{-1}$, respectively. At the end of the cycle, the best concentration of nitrogen in soil solution was of $336 \mathrm{mg} \mathrm{L}^{-1}$ and potassium ranged from 35 and $44 \mathrm{mg} \mathrm{L}^{-1}$.
\end{abstract}

Key words: Cucumis melo L, ionic concentration, porous ceramic cup extractors, nitrogen, potassium

1Parte da Tese apresentada pelo primeiro autor à ESALQ/USP. Financiada com recursos do CNPq

2DCAT/UFERSA, BR 110, km 47, CP 137, CEP 59625-900, Mossoró, RN, Fone: (84) 3315-1740. E-mail: mjanuario@ufersa.edu.br; jfmedeir@ufersa.edu.br idutra@ufersa.edu.br

3ESALQ/USP, Av. Pádua Dias 11, CP 09, CEP 13418-900, Piracicaba, SP, Fone: (19) 3447-8543. E-mail: snduarte@esalq.usp.br; thikaoamigao@hotmail.com 


\section{INTRODUÇÃO}

A fertigação é uma das atividades de maior desenvolvimento e crescimento na agricultura irrigada e deve ser feita de maneira racional, obedecendo às características de absorção de cada cultura em cada estádio de desenvolvimento, às práticas culturais necessárias durante o ciclo produtivo, à distribuição dos nutrientes no perfil do solo e à eficiência do sistema de irrigação (Bar-Yosef, 1999).

Tradicionalmente, o manejo da fertigação é realizado por meio de quantidades preestabelecidas de fertilizantes, parceladas de acordo com a marcha de absorção da cultura. Com isto, o manejo da fertigação é baseado, normalmente, em estimativas, que podem conduzir a uma aplicação excessiva de fertilizantes causando, além da lixiviação dos nutrientes e a consequente poluição do aquifero (Jiménez et al., 2006), gastos excessivos com fertilizantes e a salinização dos solos.

Os parâmetros nutricionais que constituem a base do manejo da fertigação em tempo real para cultivos em estufa, tanto em solo como em hidroponia, são o pH e a condutividade elétrica mas este controle pode, algumas vezes, ser insuficiente.

Os custos com adubo, irrigação e mão-de-obra, constituem fatores importantes na exploração das culturas irrigadas; desta forma, alternativas que preconizam a racionalização desses custos precisam ser avaliadas tendo, como relevância, o monitoramento da adição desses fertilizantes, a fim de assegurar que os produtos obtenham alto valor comercial e ambiental.

Neste sentido, a utilização de extratores de solução do solo para fins de manejo da fertigação foi avaliada por alguns pesquisadores (Blanco et al., 2008; Dias et al., 2006; Silva et al., 2000). Em resumo, esses trabalhos enfocaram a questão da utilização dos extratores como forma de se estimar a concentração de íons na solução do solo; a sensibilidade de testes rápidos na detecção desses íons no extrato da solução; o controle da salinidade através do uso de extratores e a resposta de algumas culturas ao manejo controlado da salinidade do solo, comparativamente com o manejo tradicional da fertigação. Lao et al. (2003) encontraram um modelo linear simples para estimar a composição real da solução do solo a partir umidade do solo e da composição da solução do solo. Em todos os trabalhos os resultados mostraram tendências promissoras quanto ao uso dos extratores, mas em nenhum deles se estudou a melhor concentração dos íons na solução do solo; assim, o manejo da fertigação com o uso de extratores de solução de cápsula porosa surge como alternativa econômica e ambiental; entretanto, ainda precisa ser estudado o manejo da fertigação com o controle da concentração dos íons específicos na solução do solo para servir de forma de decisão do evento de fertigação; para isto, são necessários estudos para verificar a resposta das principais culturas fertirrigadas ao manejo controlado de íons da solução do solo e calibrar a metodologia para que ela possa ser efetivamente recomendada. Dias et al. (2004) citam, como resultados preliminares, concentrações adequadas de nitrato e potássio na solução do solo para as culturas do tomate, pimentão e pepino. Lao et al. (2004), estudando a solução do solo em solo de casas de vegetação comerciais cultivadas com tomateiros, encontraram valores médios de nitrato e potássio, de 12,7 e $6,0 \mathrm{mmol}_{\mathrm{c}} \mathrm{L}^{-1}$, respectivamente.

Em virtude do exposto, esta pesquisa foi realizada com o objetivo de estudar a resposta da cultura do meloeiro quando submetida a diferentes concentrações controladas de nitrogênio-nitrato e potássio, na solução do solo.

\section{MATERIAL E MÉTODOS}

\section{Caracterização do local experimental}

O experimento foi realizado em casa de vegetação, localizada no Campus da Universidade Federal Rural do Semiárido - UFERSA, em Mossoró, RN (5 $5^{\circ} 11^{\prime}$ LS; 37²0' LO e 18 m de altitude), cuja temperatura média anual é de $27,4^{\circ} \mathrm{C}$, a umidade relativa do ar é de $68,9 \%$ e a precipitação pluviométrica é de $673,9 \mathrm{~mm}$, sendo esta bastante irregular e se concentrando nos primeiros meses do ano. Segundo a classificação de Koeppen, o clima é do tipo BSwh', ou seja, quente e seco cujo período chuvoso se adianta para o outono.

\section{Tratamento e delineamento experimental}

Adotaram-se, para definição dos tratamentos, 5 níveis de concentração de nitrogênio-nitrato e cinco níveis de concentração potássio, na solução do solo, combinados através de uma matriz denominada quadrado duplo, para formar 13 tratamentos. A matriz experimental ou arranjo de tratamentos é definida segundo o modelo: $2 \times 2^{\mathrm{k}}+2 \mathrm{k}+1$, sendo $\mathrm{k}$ o número de fatores estudados (Alvarez, 1994); assim, os tratamentos de $\mathrm{N}_{-} \mathrm{NO}_{3}$ e K em relação a uma concentração considerada padrão (100\%) ficaram definidos como: 0-0, 0-100, 0-200, 50-50, 50-150, 100-0, 100-100, 100-200, 150-50, 150-150, 200-0, 200-100 e 200-200\%. O nível zero foi determinado como o valor da concentração de $\mathrm{N}-\mathrm{NO}_{3}$ e $\mathrm{K}$ encontrada na solução do solo em condições naturais.

As concentrações padrão de nitrogênio-nitrato e de potássio, foram definidas a partir daquelas recomendadas por Castellane \& Araújo (1994) para o cultivo hidropônico do meloeiro, além de ajustadas para 168 e $84 \mathrm{mg} \mathrm{L}^{-1}$, respectivamente.

$\mathrm{O}$ delineamento experimental adotado foi o inteiramente aleatorizado com 4 repetições, totalizando 52 parcelas, em que cada parcela foi representada por um vaso de plástico com aproximadamente $20 \mathrm{~L}$ de capacidade, no qual se cultivaram duas plantas.

\section{Curva de retenção e de calibração dos tratamentos}

Construiu-se a curva de retenção de umidade simulandose uma condição real de irrigação e evaporação em casa de vegetação, para o que se utilizaram vasos com solo acondicionado, distribuídos na casa de vegetação e se instalaram tensiômetros a 0,20 m de profundidade. Com o auxílio de espaguetes o solo foi lentamente saturado e após a drenagem livre o fornecimento de água foi cortado; ao final da drenagem do excesso de água, iniciaram-se as medições das tensões com um tensímetro digital e de umidade através da co- 
leta de amostras que foram secadas em estufa de circulação forçada. Essas medições se estenderam durante quinze dias, aproximadamente, quando se observou uma baixa umidade no solo. Os dados de umidade foram plotados em gráfico, em função da tensão medida, ajustando-se uma equação potencial, que foi usada no cálculo da umidade do solo para o manejo da irrigação (Figura 1).

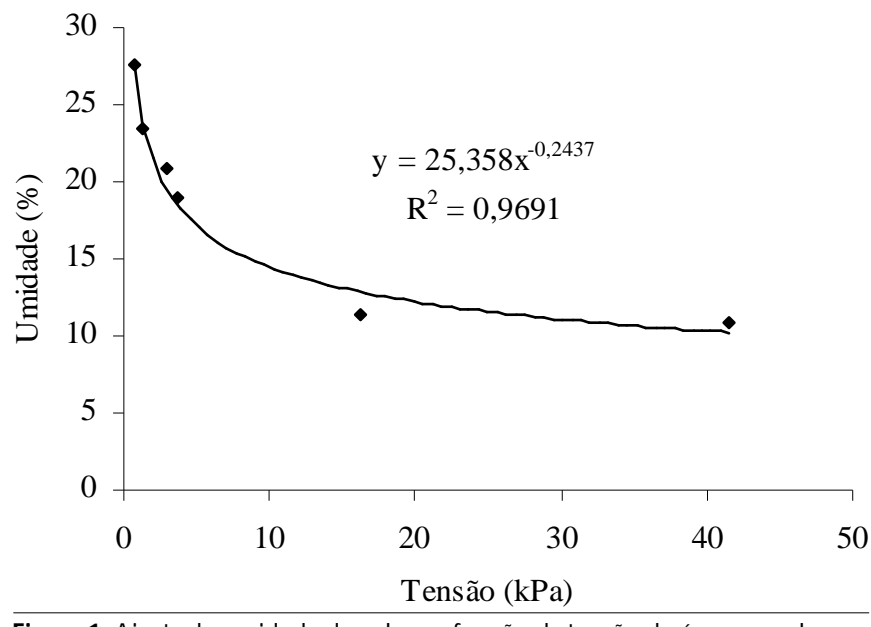

Figura 1. Ajuste da umidade do solo em função da tensão da água no solo

A construção das curvas de calibração dos tratamentos consistiu em se preparar soluções com concentrações crescentes conhecidas dos nutrientes estudados $\left(\mathrm{N}-\mathrm{NO}_{3}\right.$ e K), e aplicá-las ao solo acondicionado nos vasos com extratores instalados. O volume de solução aplicado foi ajustado para elevar a umidade do solo a máxima capacidade de retenção (capacidade de campo) e a superfície do solo foi coberta com plástico para não perder umidade; após a adição da solução fertilizante aplicou-se vácuo aos extratores e, no dia seguinte, se retirou o extrato da solução do solo.

As concentrações de $\mathrm{N}-\mathrm{NO}_{3}$ e $\mathrm{K}$ foram medidas no extrato e posteriormente se ajustou uma equação para a concentração do íon na solução fertilizante em função da concentração desse íon na solução do solo (Figura 2). Utilizaram-se essas equações a fim de se calcular a concentração do nutriente na solução fertilizante tendo em vista a necessidade de se repor a concentração desse nutriente na solução do solo para ajustá-la ao valor do tratamento.

\section{Cultura, solo e plantio}

A cultura utilizada foi o meloeiro (Cucumis melo L.) do tipo cantaloupe, híbrido Dom Luiz da SAKATA, o qual possui ampla aceitabilidade nos mercados interno e externo.

O solo utilizado no experimento foi coletado em local ainda não cultivado, sendo do tipo Cambissolo Eutrófico com textura argilosa, com as seguintes características físicas e químicas: $\mathrm{pH}$ - 7,1; M.O. - 1,7\%; P - 5,0 mg dm ${ }^{-3}$; K - 0,87; Na - 0,79; Ca - 4,00; Mg - 1,10; $\mathrm{Al}-0,00 ; \mathrm{H}-2,48 \mathrm{mmol}_{\mathrm{c}} \mathrm{dm}^{-3} ; \mathrm{d}$ - $1.300 \mathrm{~kg} \mathrm{~m}^{-3}$; areia - 450; silte - 250 e argila $-300 \mathrm{~g} \mathrm{~kg}^{-1}$; depois de coletado, o solo foi destorroado e acondicionado em vasos formados por baldes plásticos de $20 \mathrm{~L}$ de capacidade, compactando-o o suficiente para caber $24 \mathrm{~kg}$ de solo em cada vaso. Os vasos foram dispostos em linhas, no espaçamento

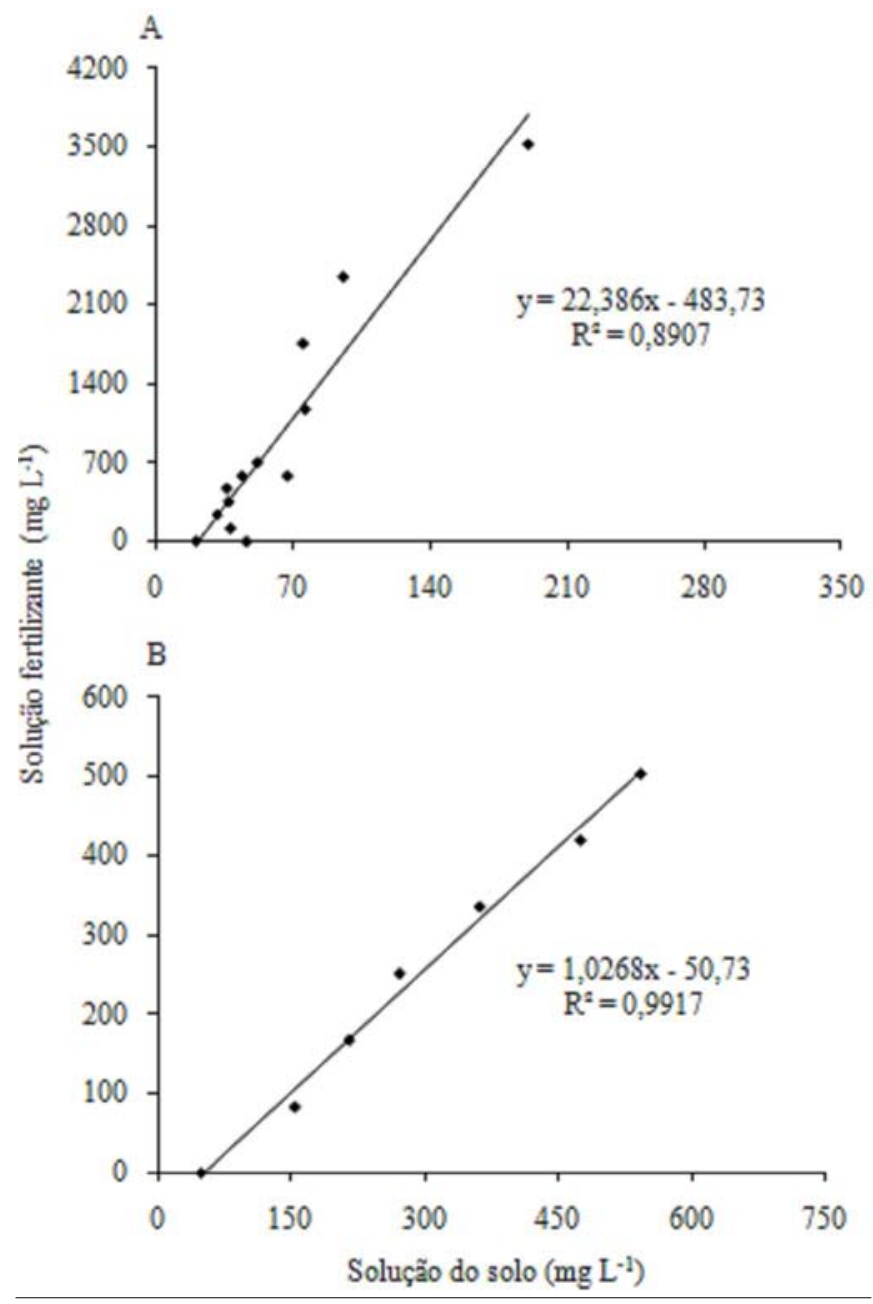

Figura 2. Ajuste da concentração de potássio (A) e nitrogênio (B) na solução fertilizante em função da concentração de nitrogênio e potássio na solução do solo

de $1,0 \times 0,5 \mathrm{~m}$, enquanto o plantio foi realizado através de semeadura direta nos vasos, no dia 23 de abril de 2008, colocando-se quatro sementes por vaso cuja germinação se deu 5 dias após.

\section{Tratos culturais}

Após a germinação fez-se o raleamento das plantas deixando-se duas por vaso, até a fase de floração plena, quando uma planta foi retirada para ser avaliada e, a partir desta fase, uma planta foi conduzida até a produção; manteve-se a cultura no "limpo" fazendo-se tantas capinas quantas fossem necessárias; para o controle de pragas e doenças adotou-se o manejo preventivo utilizandose produtos e formulações adotadas pelos produtores da região; a cultura foi tutorada verticalmente por fitilhos amarrados a espaldeiras verticais instaladas ao longo da linha de plantio, enquanto os ramos laterais, localizados abaixo do primeiro fio da espaldeira $(0,40 \mathrm{~m}$ da superfície do vaso) foram desbrotados e os demais conduzidos juntamente com a haste principal. A polinização foi manual, esfregando-se a flor masculina nas flores femininas e hermafroditas. Acomodaram-se os frutos em redes de nylon amarradas aos fios das espaldeiras. 


\section{Sistema de irrigação e manejo da água}

Um sistema de irrigação foi adotado por gotejamento utilizando-se emissores do tipo espaguete com vazão controlada para $1,76 \mathrm{~L} \mathrm{~h}^{-1}$. O sistema de irrigação foi equipado com caixa d'água suspensa com nível controlado por boia, linha de derivação, válvulas manuais e linhas laterais; em cada vaso se instalou um espaguete.

O manejo da irrigação foi baseado em dados de tensão da água no solo obtidos com o auxílio de tensiômetros instalados a 0,20 $\mathrm{m}$ de profundidade que foram convertidos em umidade com o auxílio da curva característica de retenção de água no solo (Figura 1); desta forma, as irrigações sempre foram realizadas para repor o volume de água necessário a fim de elevar a umidade atual do solo à umidade da capacidade de campo.

\section{Extração e monitoramento da solução do solo}

Obteve-se a solução do solo utilizando-se extratores munidos de cápsulas cerâmicas em sua extremidade inferior e borrachas especiais com vedação de silicone na extremidade superior. Os extratores foram instalados a 0,10 e $0,20 \mathrm{~m}$ de profundidade e a eles foi promovida uma tensão de aproximadamente $80 \mathrm{kPa}$ através da sucção do ar contido no seu interior.

A retirada da solução dos extratores se deu com seringa e um espaguete acoplado à seringa; a solução extraída foi acondicionada em recipientes plásticos para, posteriormente, ser analisada; realizaram-se as análises de $\mathrm{N}-\mathrm{NO}_{3}$ com o uso de uma cartela de teste rápido da marca Horiba, enquanto as de potássio foram analisadas através da fotometria de emissão de chama.

Toda vez em que se coletou solução do solo fez-se, antes da irrigação e também se mediu, a tensão da água no solo por meio dos tensiômetros instalados, para que as concentrações medidas fossem corrigidas para a umidade da capacidade de campo, de acordo com a equação a seguir:

$$
\mathrm{C}_{\mathrm{mc}}=\frac{\mathrm{U}_{\mathrm{a}}}{\mathrm{U}_{\mathrm{cc}}} \times \mathrm{C}_{\mathrm{ma}}
$$

em que:

$\mathrm{C}_{\mathrm{mc}}$ - Concentração medida do nutriente, corrigida para a umidade da capacidade de campo, $\mathrm{mg} \mathrm{L}^{-1}$

$\mathrm{U}_{\mathrm{a}}$ - Umidade atual do solo, $\mathrm{kg} \mathrm{kg}^{-1}$

$\mathrm{U}_{\mathrm{cc}}$ - Umidade do solo na capacidade de campo, $\mathrm{kg} \mathrm{kg}^{-1}$

$\mathrm{C}_{\mathrm{ma}}$ - Concentração medida do nutriente na umidade atual do solo, $\mathrm{mg} \mathrm{L}^{-1}$

\section{Fertigação e manejo dos tratamentos}

Aplicou-se ao solo, antes do plantio, uma solução fertilizante contendo todos os macronutrientes em volume suficiente para elevar a umidade atual do solo à umidade da capacidade de campo. A concentração de nitrogênio e de potássio foi ajustada através das curvas de calibração dos tratamentos para disponibilizar, na solução do solo, a concentração desejada para cada tratamento, enquanto os demais nutrientes permaneceram constantes, com a seguinte composição: $\mathrm{P}$ - 31; Ca - 160; Mg - 24 e S - 32 mg L ${ }^{-1}$.
Ao longo do ciclo se realizaram as aplicações dos fertilizantes nitrogenados e potássicos de acordo com a concentração de nitrogênio e potássio na solução do solo. Quando se detectou, através da análise da solução do solo, uma diferença superior a $20 \%$ entre a concentração medida e a desejada, realizou-se uma aplicação de solução fertilizante com concentração calculada para atingir, na solução do solo, o valor projetado para o tratamento, como segue:

$$
\operatorname{Se}\left\{\begin{array}{l}
\left(\mathrm{C}_{\mathrm{d}}-\mathrm{C}_{\mathrm{mc}}\right)<0 \Rightarrow \mathrm{R}_{\mathrm{c}}=0 \\
\left(\mathrm{C}_{\mathrm{d}}-\mathrm{C}_{\mathrm{mc}}\right)<0,2 \times \mathrm{C}_{\mathrm{d}} \Rightarrow \mathrm{R}_{\mathrm{c}}=0 \\
\left(\mathrm{C}_{\mathrm{d}}-\mathrm{C}_{\mathrm{mc}}\right) \geq 0,2 \times \mathrm{C}_{\mathrm{d}} \Rightarrow \mathrm{R}_{\mathrm{c}}=\mathrm{C}_{\mathrm{d}}-\mathrm{C}_{\mathrm{mc}}
\end{array}\right.
$$

em que:

$\mathrm{C}_{\mathrm{d}}$ - Concentração desejada do nutriente na solução do solo, $\mathrm{mg} \mathrm{L}^{-1}$

$\mathrm{R}_{\mathrm{c}}$ - Reposição de concentração, $\mathrm{mg} \mathrm{L}^{-1}$

Para calcular a concentração do nutriente na solução de fertigação necessária para atingir o valor da reposição na solução do solo, se utilizaram as curvas de calibração dos tratamentos (Figura 2).

Os adubos contendo fósforo, cálcio, magnésio e enxofre, foram suprimidos nos primeiros 50 dias e posteriormente aplicados em todos os eventos de fertigação nas concentrações inicialmente adicionadas.

O volume de solução aplicado em cada evento de fertigação foi o suficiente para elevar a umidade atual do solo à umidade da capacidade de campo. As fertigações foram feitas manualmente com o uso de proveta para medir o volume de solução e, quando não foi necessário utilizar adubo, aplicou-se apenas água, através do sistema de irrigação.

Utilizaram-se, como fertilizantes, os seguintes produtos: nitrato de cálcio, cloreto de potássio, fosfato monobásico de potássio, nitrato de potássio, nitrato de sódio, cloreto de cálcio, sulfato de magnésio e ácido fosfórico.

\section{Parâmetros avaliados}

Com a primeira planta, retirada aos 31 dias após a semeadura (DAS), se avaliaram os seguintes parâmetros: comprimento da haste principal, diâmetro do caule, número de folhas, área foliar, área foliar média e matéria seca total da parte aérea; já com a segunda planta, retirada aos 87 DAS, foram avaliados os seguintes parâmetros vegetativos: número de folhas, área foliar, área foliar média, matéria seca do caule, das folhas e dos frutos e matéria seca total da parte aérea.

Para determinação dessas variáveis procedeu-se da seguinte forma: quanto ao comprimento da haste, mediu-se a planta desde o colo até o ápice da haste principal; diâmetro do caule: mediu-se o diâmetro do colo com um paquímetro; número de folhas: separam-se as folhas da planta e se procedeu à contagem; na área foliar, fez-se a integração da área do limbo foliar de todas as folhas da planta, através de um integrador da marca LICOR modelo LI-3100; a área foliar média, foi obtida através da divisão entre a área foliar e o número de folhas; por fim obteve-se a matéria seca das partes da planta secando-se o material em estufa de circulação forçada, sendo que a matéria seca total da parte aérea foi obtida pela soma das matérias secas das partes individuais. 


\section{Análise dos dados}

Análises de variância e de regressão foram realizadas desdobrando-se os graus de liberdade dos tratamentos em efeitos de regressão lineares e quadráticos e em interações entre esses efeitos. Com os efeitos de regressão significativos $(\mathrm{p} \leq 0,05)$, ajustou-se a equação de regressão para explicar o comportamento dos dados. Em todas essas análises foram utilizados os procedimentos do aplicativo SAS. As estimativas dos parâmetros dos modelos ajustados foram submetidas ao teste F com o auxílio do aplicativo FCalcw para identificar o nível de significância de cada parâmetro em função do quadrado médio do resíduo da análise de variância, sendo considerados significativos aqueles com $\mathrm{p} \leq 0,05$.

\section{RESULTADOS E DISCUSSÃO}

Aos 31 dias após a semeadura (DAS), o comprimento da haste principal foi influenciado tanto pelo aumento da concentração de nitrogênio na solução do solo como pelo aumento da concentração de potássio e pela interação desses dois nutrientes (Tabela 1). Para o nitrogênio, o efeito foi negativo, ou seja, diminuiu até atingir um ponto mínimo, aumentando posteriormente; já para o potássio, o efeito foi positivo, aumentando com as concentrações de potássio na solução do solo até atingir um ponto de máximo. O efeito simultâneo de crescimento para um fator e decrescimento para outro, resulta em um ponto crítico que não é máximo nem mínimo; com isto, os valores dos fatores que tornam máxima a função, é a manutenção de $336 \mathrm{mg} \mathrm{L}^{-1}$ de nitrogênio e $18 \mathrm{mg} \mathrm{L}^{-1}$ de potássio na solução do solo, cujo valor é da ordem de $0,91 \mathrm{~m}$.

Tabela 1. Comprimento da haste principal das plantas de meloeiro "cantaloupe" aos 31 dias após a semeadura, em função da concentração de nitrogênio (N) e potássio (K) na solução do solo

\begin{tabular}{|c|c|c|c|c|c|c|}
\hline \multirow{3}{*}{$\begin{array}{l}\text { Concentração- } \\
\text { de N (mg L-1) }\end{array}$} & \multicolumn{5}{|c|}{ Concentração de $\mathrm{K}\left(\mathrm{mg} \mathrm{L}^{-1}\right)$} & \multirow{3}{*}{ Média } \\
\hline & 0 & 21 & 42 & 63 & 84 & \\
\hline & \multicolumn{5}{|c|}{ Comprimento da haste } & \\
\hline 0 & 0,68 & - & 0,70 & - & 0,78 & 0,72 \\
\hline 84 & - & 0,79 & - & 0,92 & - & 0,85 \\
\hline 168 & 0,91 & - & 0,79 & - & 0,07 & 0,59 \\
\hline 252 & - & 0,73 & - & 0,90 & - & 0,81 \\
\hline 336 & 0,88 & - & 0,86 & - & 0,91 & 0,88 \\
\hline Média & 0,82 & 0,76 & 0,78 & 0,91 & 0,59 & 0,77 \\
\hline Equação: & \multicolumn{5}{|c|}{$\begin{array}{c}Y=0,78 * *-0,0014 * * N+0,0075 * * K+ \\
0,0000052 * N^{2}-0,00012 * * K^{2}-0,0000000058 * * N^{2} K \\
+0,0000000009 * * N^{2} K^{2}\end{array}$} & $R^{2}=0,450$ \\
\hline
\end{tabular}

${ }^{*} \mathrm{e}^{* *}:$ Significativo a $5 \%$ e a $1 \%$ de probabilidade, respectivamente. ns: não significativo

Monteiro et al. (2008) estudando a influência do gotejamento subterrâneo e do "mulching" plástico na cultura do melão em ambiente protegido encontraram, para o solo de textura argilosa aos 29 dias após o transplantio, alturas de planta variando de 0,62 a 1,17 m; já Vásquez (2003) testando o efeito da fertigação com diferentes doses de potássio e lâ- minas de irrigação em gotejamento superficial e subsuperficial encontrou, para as doses de potássio estudadas, alturas médias de planta variando de 0,46 a $0,65 \mathrm{~m}$ aos 24 dias após o transplantio e de 0,60 a $0,81 \mathrm{~m}$ aos 31 dias após o transplantio; por outro lado, Rizzo et al. (2000) encontraram altura média das plantas aos 45 dias após o transplantio de 1,59 m.

Observa-se, portanto, que os comprimentos médios da haste principal obtidos neste experimento estão dentro da faixa de variação observada em outras pesquisas, sinal de que as plantas tiveram boas condições de desenvolvimento, talvez pela alta fertilidade natural observada para este solo.

O diâmetro do caule avaliado aos 31 DAS apresentou efeito de interações das concentrações de nitrogênio e potássio na solução do solo e cresceu não apenas com o incremento do nitrogênio, mas, também, com o incremento do potássio disponível na solução do solo. O efeito para os dois fatores foi quadrático; entretanto, devido às interações, a função assume um valor máximo de $8,58 \mathrm{~mm}$ para a combinação da adição de $0 \mathrm{mg} \mathrm{L}^{-1}$ de nitrogênio em fertigação e manutenção de $84 \mathrm{mg} \mathrm{L}^{-1}$ de potássio na solução do solo (Tabela 2).

Tabela 2. Diâmetro do caule das plantas de meloeiro "cantaloupe" aos 31 dias após a semeadura, em função da concentração de nitrogênio (N) e potássio (K) na solução do solo

\begin{tabular}{|c|c|c|c|c|c|c|}
\hline \multirow{3}{*}{$\begin{array}{l}\text { Concentração- } \\
\text { de } \mathbf{N}\left(\mathrm{mg} \mathrm{L}^{-1}\right)\end{array}$} & \multicolumn{5}{|c|}{ Concentração de $\mathrm{K}\left(\mathrm{mg} \mathrm{L}^{-1}\right)$} & \multirow{3}{*}{ Média } \\
\hline & 0 & 21 & 42 & 63 & 84 & \\
\hline & \multicolumn{5}{|c|}{ Comprimento do caule (mm) } & \\
\hline 0 & 7,58 & - & 7,58 & - & 8,63 & 7,93 \\
\hline 84 & - & 7,80 & - & 7,48 & - & 7,64 \\
\hline 168 & 7,73 & - & 7,88 & - & 3,85 & 6,48 \\
\hline 252 & - & 7,35 & - & 7,75 & - & 7,55 \\
\hline 336 & 8,10 & - & 7,78 & - & 8,28 & 8,05 \\
\hline Média & 7,80 & 7,58 & 7,74 & 7,61 & 6,92 & 7,53 \\
\hline
\end{tabular}
$0,000000022 * * N^{2} K^{2}$

${ }^{*} \mathrm{e}^{* *}$ : Significativo a $5 \%$ e a $1 \%$ de probabilidade, respectivamente. ns: não significativo

No estudo de Monteiro et al. (2008), os valores de diâmetro do colo das plantas observados aos 29 dias após o transplantio, variaram de 5,8 a $8,2 \mathrm{~mm}$, enquanto no trabalho de Dias et al. (2006), os valores médios observados aos 34 dias após o transplantio variaram entre 7,0 e 9,0 mm. Como os valores para esta variável estão dentro da variação observada por outros pesquisadores têm-se, mais uma vez, indícios de que as plantas tiveram boas condições de desenvolvimento.

O número de folhas emitidas aos 31 DAS aumentou de forma quadrática quando se incrementaram as concentrações de nitrogênio e potássio; entretanto, devido aos efeitos das interações ocorridas entre os fatores estudados, o número máximo de folhas estimado foi de 93,28 folhas, quando se utilizaram os níveis máximos de nitrogênio e potássio, ou seja, 336 e $84 \mathrm{mg} \mathrm{L}^{-1}$, respectivamente (Tabela 3).

Em ambiente protegido com solo argiloso, Vásquez (2003) encontrou número médio de folhas por planta variando de 4,4 a 10,3 folhas aos 24 dias e de 6,9 a 14,9 folhas aos 31 dias, 
Tabela 3. Número de folhas, área foliar e área foliar média das plantas de meloeiro "cantaloupe" aos 31 dias após a semeadura, em função da concentração de nitrogênio (N) e potássio (K) na solução do solo

\begin{tabular}{|c|c|c|c|c|c|c|}
\hline \multirow{2}{*}{$\begin{array}{l}\text { Concentração } \\
\text { de } \mathbf{N}\left(\mathrm{mg} \mathrm{L}^{-1}\right)\end{array}$} & \multicolumn{5}{|c|}{ Concentração de $K\left(\mathrm{mg} \mathrm{L}^{-1}\right)$} & \multirow{2}{*}{ Média } \\
\hline & 0 & 21 & 42 & 63 & 84 & \\
\hline \multicolumn{7}{|c|}{ Número de folhas } \\
\hline 0 & 14,00 & - & 17,25 & - & 17,50 & 14,00 \\
\hline 84 & - & 17,00 & - & 14,25 & - & - \\
\hline 168 & 18,25 & & 17,00 & 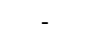 & 5,75 & 18,25 \\
\hline 252 & - & 11,50 & - & 13,25 & - & - \\
\hline 336 & 17,00 & - & 15,00 & - & 19,00 & 17,00 \\
\hline Média & 16,42 & 14,25 & 16,42 & 13,75 & 14,08 & 16,42 \\
\hline \multicolumn{7}{|c|}{$\begin{array}{c}Y=14,25 * *+0,023 * * N+0,12 * * K-0,000051 * N^{2} \\
-0,00099 * * K^{2}-0,0000024^{*} * N^{2} K-0,000023^{*} * N^{2} \\
+0,0000001^{* *} N^{2} K^{2}\end{array}$} \\
\hline \multicolumn{7}{|c|}{ Área foliar $\left(\mathrm{cm}^{2}\right)$} \\
\hline 0 & 719,20 & & 982,00 & - & $1.049,65$ & 916,95 \\
\hline 84 & - & $1.030,56$ & - & 870,84 & - & 950,70 \\
\hline 168 & $1.102,35$ & - & $1.056,28$ & - & 110,66 & 756,43 \\
\hline 252 & & 793,96 & & 839,04 & - & 816,50 \\
\hline 336 & 920,32 & - & 887,69 & - & $1.130,29$ & 979,43 \\
\hline Média & 913,96 & 912,26 & 975,32 & 854,94 & 763,53 & 884,00 \\
\hline Equação: & $\begin{array}{r}Y=706,13 \\
-0,087^{*}\end{array}$ & $\begin{array}{r}* *+3,41 * \\
* K^{2}-0,000 \\
0,000\end{array}$ & $\begin{array}{l}* N+11 \\
14 * * N^{2} K \\
10074 * N^{2}\end{array}$ & $\begin{array}{l}6 * * \mathrm{~K}-0, \\
0,0020 * * \\
2^{2}\end{array}$ & $\begin{array}{l}0086 * * N^{2} \\
N^{2}+\end{array}$ & $R^{2}=0,891$ \\
\hline \multicolumn{7}{|c|}{$\begin{array}{c}0,0000074 * \mathrm{~N}^{2} \mathrm{~K}^{2} \\
\text { Área foliar média }\left(\mathrm{cm}^{2}\right)\end{array}$} \\
\hline 0 & 51,77 & - & 56,36 & - & 58,82 & 55,65 \\
\hline 84 & - & 61,10 & - & 61,43 & - & 61,27 \\
\hline 168 & 60,79 & - & 62,41 & - & 18,62 & 47,27 \\
\hline 252 & - & 69,34 & - & 63,18 & - & 66,26 \\
\hline 336 & 54,11 & - & 59,66 & - & 59,36 & 57,71 \\
\hline Média & 55,56 & 65,22 & 59,48 & 62,30 & 45,60 & 57,63 \\
\hline Equação: & \multicolumn{5}{|c|}{$\begin{array}{c}Y=57,66^{* *}-0,056^{* *} N+0,55^{* *} K+0,00016^{* *} N^{2} \\
-0,0084^{* *} K^{2}-0,00000087^{n s} N^{2} K+ \\
0,00000002^{n s} N^{2} K^{2}\end{array}$} & $R^{2}=0,883$ \\
\hline
\end{tabular}

${ }^{*} \mathrm{e}^{* *}$ : Significativo a $5 \%$ e a $1 \%$ de probabilidade, respectivamente. ns: não significativo

ambos após o transplantio, para doses de potássio variando de 0 a $12 \mathrm{~g}$ de $\mathrm{K}_{2} \mathrm{O}$ por planta, sendo que o maior resultado foi obtido com a dose de $9 \mathrm{~g}$ de $\mathrm{K}_{2} \mathrm{O}$ por planta.

Apesar da boa representatividade do modelo ajustado $\left(\mathrm{R}^{2}\right.$ $=0,836)$, a estimativa do número máximo de folhas $(93,28)$ ficou muito acima dos valores médios observados, tanto neste experimento quanto em experimentos similares sendo, portanto, os valores apresentados na Tabela 2 , mais representativos da realidade que, inclusive, estão acima dos valores observados em outros trabalhos.

A área foliar também mostrou crescimento com o aumento das concentrações de nitrogênio e potássio, de forma quadrática; entretanto, o efeito das interações entre os fatores remete a variável a um valor máximo de $1.133,3 \mathrm{~cm}^{2}$ obtido com as concentrações de 336 e $84 \mathrm{mg} \mathrm{L}^{-1}$, respectivamente de nitrogênio e potássio (Tabela 3 ).

No estudo de Vásquez (2003), para as doses de potássio foram observadas áreas foliares variando de $700 \mathrm{a} 1.090 \mathrm{~cm}^{2}$ aos 24 dias e de 1.330 a $1.870 \mathrm{~cm}^{2}$ aos 31 dias, ambas após o transplantio.

Observa-se que, apesar do efeito quadrático, valores máximos para número de folhas e área foliar foram obtidos com os maiores níveis dos fatores estudados, indicando que é possível se aumentar os valores dessas variáveis caso se aumentem, também, as concentrações de nitrogênio e potássio na solução do solo; por outro lado, e se considerando que os valores observados estão compatíveis com outros estudos, talvez esta combinação de concentração seja a mais favorável à cultura.

A área foliar média apresentou efeito quadrático para as concentrações de nitrogênio e de potássio, caso em que ela diminuiu com o aumento do nitrogênio, mas aumentou com o incremento do potássio. Tendo em vista a ocorrência de interações entre os fatores, a maior área foliar média observada foi de $66,45 \mathrm{~cm}^{2}$ obtida com a aplicação de $0 \mathrm{mg} \mathrm{L}^{-1}$ de nitrogênio na fertigação e a manutenção de $32 \mathrm{mg} \mathrm{L}^{-1}$ de potássio na solução do solo.

Para a matéria seca avaliada aos 31 dias após a semeadura, observou-se efeito quadrático, tanto do nitrogênio quanto do potássio. Como se deu redução do valor da função com os termos lineares, deveria haver um valor crítico de mínimo; entretanto, devido ao efeito das interações observadas, a matéria seca assumiu um valor máximo de 19,07 g por planta, quando a solução do solo foi mantida com concentração de nitrogênio e potássio, respectivamente de 336 e $84 \mathrm{mg} \mathrm{L}^{-1}$ (Tabela 4).

Tabela 4. Matéria seca total da parte aérea das plantas de meloeiro "cantaloupe" aos 31 dias após a semeadura, em função da concentração de nitrogênio (N) e potássio (K) na solução do solo

\begin{tabular}{|c|c|c|c|c|c|c|}
\hline \multirow{3}{*}{$\begin{array}{l}\text { Concentração } \\
\text { de } N\left(\mathrm{mg} \mathrm{L}^{-1}\right)\end{array}$} & \multicolumn{5}{|c|}{ Concentração de $\mathrm{K}\left(\mathrm{mg} \mathrm{L}^{-1}\right)$} & \multirow{3}{*}{ Média } \\
\hline & 0 & 21 & 42 & 63 & 84 & \\
\hline & \multicolumn{5}{|c|}{ Matéria seca total da parte aérea (g planta-1) } & \\
\hline 0 & 12,95 & - & 12,72 & - & 17,61 & 14,43 \\
\hline 84 & - & 14,62 & - & 13,45 & - & 14,03 \\
\hline 168 & 16,38 & - & 14,14 & - & 7,32 & 12,61 \\
\hline 252 & - & 12,71 & - & 14,66 & - & 13,68 \\
\hline 336 & 13,92 & - & 12,81 & - & 16,09 & 14,27 \\
\hline Média & 14,42 & 13,66 & 13,22 & 14,05 & 13,67 & 13,80 \\
\hline Equação: & \multicolumn{5}{|c|}{$\begin{array}{c}Y=15,12^{* *}-0,016^{* *} N-0,0068^{n s} K+ \\
0,000042^{* *} N^{2}+0,00011^{n s} K^{2}-0,00000037^{n s} N^{2} K+ \\
0,00000001^{n s} N^{2} K^{2}\end{array}$} & $R^{2}=0,825$ \\
\hline
\end{tabular}

${ }^{*} \mathrm{e}^{* *}$ : Significativo a $5 \%$ e a $1 \%$ de probabilidade, respectivamente ns: não significativo

Para o melão Gold mine cultivado em condições de campo em solo de textura franco-argilo-arenosa, constatou-se uma fitomassa seca de 16,07 g por planta, aos 34 dias após o plantio (Farias et al., 2003).

O número de folhas aos 87 DAS, ocasião em que ocorreu o final do ciclo de cultivo, aumentou de forma quadrática quando se incrementaram as concentrações de nitrogênio e potássio; entretanto, em virtude da ocorrência de interação entre os fatores estudados, o valor máximo assumido pela função ajustada (140 folhas), foi obtido com as concentrações de 336 e $44 \mathrm{mg} \mathrm{L}^{-1}$ de $\mathrm{N}$ e K, respectivamente (Tabela 5).

Observa-se, para a área foliar avaliada no mesmo período, que ela cresceu de forma quadrática, tanto para o nitrogênio como para o potássio e que o valor máximo 
Tabela 5. Número de folhas, área foliar e área foliar média das plantas de meloeiro "cantaloupe" aos 87 dias após a semeadura, em função da concentração de nitrogênio $(\mathrm{N})$ e potássio (K) na solução do solo

\begin{tabular}{|c|c|c|c|c|c|c|}
\hline \multirow{2}{*}{$\begin{array}{l}\text { Concentração } \\
\text { de N (mg L-1) }\end{array}$} & \multicolumn{5}{|c|}{ Concentração de $\mathrm{K}\left(\mathrm{mg} \mathrm{L}^{-1}\right)$} & \multirow{2}{*}{ Média } \\
\hline & 0 & 21 & 42 & 63 & 84 & \\
\hline \multicolumn{7}{|c|}{ Número de folhas } \\
\hline 0 & 18,75 & - & 32,50 & - & 27,25 & 26,17 \\
\hline 84 & - & 54,50 & - & 65,75 & - & 60,13 \\
\hline 168 & 103,50 & 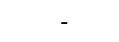 & 96,50 & - & 59,25 & 86,42 \\
\hline 252 & - & 135,00 & - & 134,75 & - & 134,88 \\
\hline 336 & 115,50 & - & 133,00 & - & 127,50 & 125,33 \\
\hline Média & 79,25 & 94,75 & 87,33 & 100,25 & 71,33 & 86,58 \\
\hline Equação: & \multicolumn{5}{|c|}{$\begin{array}{c}Y=23,69 * *+0,48 * * N+0,60 * * K-0,00056^{* *} N^{2} \\
-0,0088 * * K^{2}+0,0000016^{\text {ns }} N^{2} K\end{array}$} & $R^{2}=0,953$ \\
\hline \multicolumn{7}{|c|}{ Área foliar $\left(\mathrm{cm}^{2}\right)$} \\
\hline 0 & 925,25 & - & $1.096,00$ & - & $1.135,50$ & $1.052,25$ \\
\hline 84 & - & $2.394,50$ & - & $2.921,25$ & - & $2.657,88$ \\
\hline 168 & $3.440,25$ & - & $3.986,00$ & - & $3.004,00$ & $3.476,75$ \\
\hline 252 & - & $4.753,25$ & - & $5.033,25$ & - & $4.893,25$ \\
\hline 336 & $4.664,75$ & & $5.791,75$ & - & $4.826,75$ & $5.094,42$ \\
\hline Média & $3.010,08$ & $3.573,88$ & $3.624,58$ & $3.977,25$ & $2.988,75$ & $3.434,91$ \\
\hline Equação: & \multicolumn{5}{|c|}{$\begin{array}{c}\mathrm{Y}=757,54 * *+17,66^{* *} \mathrm{~N}+33,51 * * \mathrm{~K}-0,016 * * \mathrm{~N}^{2} \\
-0,39 * * \mathrm{~K}^{2}\end{array}$} & $R^{2}=0,978$ \\
\hline \multicolumn{7}{|c|}{ Área foliar média $\left(\mathrm{cm}^{2}\right)$} \\
\hline 0 & 56,89 & - & 39,40 & - & 41,18 & 45,82 \\
\hline 84 & - & 44,18 & - & 47,22 & - & 45,70 \\
\hline 168 & 33,59 & - & 41,24 & - & 50,36 & 41,73 \\
\hline 252 & - & 35,70 & - & 38,50 & - & 37,10 \\
\hline 336 & 40,98 & - & 44,53 & - & 38,01 & 41,17 \\
\hline Média & 43,82 & 39,94 & 41,72 & 42,86 & 43,18 & 42,30 \\
\hline Equação: & \multicolumn{5}{|c|}{$\begin{array}{c}Y=47,07^{* *}-0,045^{*} \mathrm{~N}-0,0088^{\mathrm{n}} \mathrm{K} K+0,000061^{\mathrm{ns}} \mathrm{N}^{2} \\
+0,00000032^{\mathrm{ns}} \mathrm{N}^{2} \mathrm{~K}\end{array}$} & $R^{2}=0,666$ \\
\hline
\end{tabular}

${ }^{*} \mathrm{e}^{* *}$ : Significativo a $5 \%$ e a $1 \%$ de probabilidade, respectivamente.

ns: não significativo

$\left(5.591,6 \mathrm{~cm}^{2}\right)$ assumido por esta variável decorre da manutenção de 336 e $44 \mathrm{mg} \mathrm{L}^{-1}$, respectivamente de nitrogênio e potássio na solução do solo (Tabela 5); já a área foliar média reduziu não só com o aumento de nitrogênio mas também com o aumento de potássio na solução do solo sendo que, para o nitrogênio, o efeito foi quadrático, atingindo um valor mínimo enquanto para o potássio o efeito foi linear. Como houve efeito de interação, a análise da superfície de resposta resulta no valor máximo para a variável de $47,07 \mathrm{~cm}^{2}$, obtido com as dosagens de 0 e 0 $\mathrm{mg} \mathrm{L}^{-1}$ de nitrogênio e potássio, o que corresponde à não aplicação de adubos nitrogenados e potássicos em fertigação (Tabela 5).

A área foliar máxima obtida por Dias et al. (2006) na fase reprodutiva (92 dias após o transplante) foi de $12.027 \mathrm{~cm}^{2}$; para o melão Gold mine, em condições de campo, se encontraram áreas foliares entre $8.000 \mathrm{e} 10.700 \mathrm{~cm}^{2}$ por planta no final do ciclo de cultivo, que se deu aos 62 dias após o plantio (Farias et al., 2003). O número de folhas encontrado por Vásquez (2003), para as doses de potássio aos 74 dias após o transplantio, variou de 16,1 a 31,0 folhas e a área foliar entre 3.140 a $5.780 \mathrm{~cm}^{2}$ o que oferece áreas foliares médias entre 195,0 e $181,5 \mathrm{~cm}^{2}$ caso em que o ciclo se prolongou por mais de 100 dias.
Pode-se observar, então, que na segunda metade do ciclo as plantas reduziram o ritmo de crescimento em relação à primeira metade; todavia, as plantas emitiram um bom número de folhas mas reduziram o tamanho das folhas, resultando em uma área foliar menor, podendo ser isto uma evidência de que as condições de cultivo não estavam favoráveis às plantas.

A matéria seca acumulada nas plantas e em suas partes aos 87 DAS, está apresentada na Tabela 6 , na qual se nota que a matéria seca acumulada no caule aumentou em função da concentração de nitrogênio na solução do solo e diminuiu em função da concentração de potássio. Para os dois nutrientes o efeito foi quadrático e de interação sendo que o valor máximo (13,83 g por planta) foi obtido com as concentrações de $336 \mathrm{mg} \mathrm{L}^{-1}$ de $\mathrm{N}$ e $35 \mathrm{mg} \mathrm{L}^{-1}$ de $\mathrm{K}$.

Tabela 6. Matéria seca do caule, das fol has, dos frutos e total da parte aérea das plantas de meloeiro "cantaloupe" aos 87 dias após a semeadura, em função da concentração de nitrogênio (N) e potássio (K) na solução do solo

\begin{tabular}{|c|c|c|c|c|c|c|}
\hline \multirow{2}{*}{$\begin{array}{l}\text { Concentração } \\
\text { de } \mathrm{N}\left(\mathrm{mg} \mathrm{L}^{-1}\right)\end{array}$} & \multicolumn{5}{|c|}{ Concentração de $\mathrm{K}\left(\mathrm{mg} \mathrm{L}^{-1}\right)$} & \multirow{2}{*}{ Média } \\
\hline & 0 & 21 & 42 & 63 & 84 & \\
\hline \multicolumn{7}{|c|}{ Matéria seca do caule (g planta ${ }^{-1}$ ) } \\
\hline 0 & 4,42 & - & 5,22 & - & 2,96 & 4,20 \\
\hline 84 & - & 7,28 & - & 6,97 & & 7,12 \\
\hline 168 & 18,51 & - & 10,36 & - & 5,87 & 11,58 \\
\hline 252 & - & 11,62 & - & 11,29 & & 11,45 \\
\hline 336 & 10,28 & - & 18,21 & - & 10,87 & 13,12 \\
\hline Média & 11,07 & 9,45 & 11,26 & 9,13 & 6,57 & 9,49 \\
\hline Equação: & \multicolumn{5}{|c|}{$\begin{array}{c}Y=6,51 * *+0,049 * * N-0,0024 \text { ns } K-0,00009 * * N^{2} \\
-0,00082 * K^{2}+0,00000053 * N^{2} K\end{array}$} & $R^{2}=0,932$ \\
\hline \multicolumn{7}{|c|}{ Matéria seca das folhas (g planta-1) } \\
\hline 0 & 11,10 & - & 10,87 & - & 9,17 & 10,38 \\
\hline 84 & - & 16,07 & - & 19,68 & - & 17,87 \\
\hline 168 & 26,54 & - & 27,20 & - & 18,78 & 24,17 \\
\hline 252 & - & 35,46 & - & 28,96 & - & 32,21 \\
\hline 336 & 31,28 & - & 42,48 & - & 35,06 & 36,27 \\
\hline Média & 22,97 & 25,76 & 26,85 & 24,32 & 21,00 & 24,18 \\
\hline Equação: & $Y=9,66^{*}$ & $+0,084$ & $\begin{array}{l}\mathrm{N}+0,1 \\
0025^{* *} \mathrm{~K}\end{array}$ & $k * K-0,0$ & $0017^{n s} \mathrm{~N}^{2}$ & $R^{2}=0,952$ \\
\hline \multicolumn{7}{|c|}{ Matéria seca dos frutos (g planta ${ }^{1}$ ) } \\
\hline 0 & 6,52 & - & 7,27 & - & 7,50 & 7,10 \\
\hline 84 & - & 12,25 & - & 19,91 & - & 16,08 \\
\hline 168 & 7,17 & - & 15,19 & - & 10,84 & 11,07 \\
\hline 252 & - & 16,73 & - & 22,27 & - & 19,50 \\
\hline 336 & 14,75 & - & 10,24 & - & 21,90 & 15,63 \\
\hline Média & 9,48 & 14,49 & 10,90 & 21,09 & 13,41 & 13,87 \\
\hline Equação: & \multicolumn{5}{|c|}{$\begin{array}{c}Y=5,50 * *+0,056^{* *} \mathrm{~N}+0,16^{* *} \mathrm{~K}-0,00012^{* *} \mathrm{~N}^{2} \\
-0,0016^{* *} \mathrm{~K}^{2}-0,0000010^{n s} \mathrm{NK}^{2}+ \\
0,000000012^{*} \mathrm{~N}^{2} \mathrm{~K}^{2}\end{array}$} & $R^{2}=0,810$ \\
\hline \multicolumn{7}{|c|}{ Matéria seca total da parte aérea (g planta ${ }^{1}$ ) } \\
\hline 0 & 22,04 & - & 23,36 & - & 19,63 & 21,67 \\
\hline 84 & - & 35,59 & - & 46,56 & - & 41,07 \\
\hline 168 & 52,22 & - & 52,75 & - & 35,49 & 46,82 \\
\hline 252 & - & 63,81 & - & 62,51 & - & 63,16 \\
\hline 336 & 56,31 & - & 70,93 & - & 67,84 & 65,02 \\
\hline Média & 43,52 & 49,70 & 49,01 & 54,53 & 40,98 & 47,55 \\
\hline Equação: & \multicolumn{5}{|c|}{$\begin{array}{c}Y=22,52^{* *}+0,19 * * N+0,31 * * K-0,00023^{* * N} N^{2} \\
-0,0046^{* *} K^{2}+0,0000015^{* *} N^{2} K\end{array}$} & $R^{2}=0,947$ \\
\hline
\end{tabular}


Com relação à matéria seca acumulada pelas folhas, observaram-se efeito linear do nitrogênio e do potássio aumentando a matéria seca e efeito quadrático para ambos os fatores. A análise da função ajustada indica que o maior valor de matéria seca acumulada nas folhas é da ordem de 39,48 g por planta, obtido com o uso de 336 e $37 \mathrm{mg} \mathrm{L}^{-1}$ de nitrogênio e de potássio, respectivamente (Tabela 6 ).

A matéria seca acumulada nos frutos aumentou com o incremento na concentração de nitrogênio e com o incremento na concentração de potássio havendo, também, efeitos quadráticos para os dois fatores e de interações. Apesar dos efeitos quadráticos, a ocorrência das interações fez com que o maior valor para a matéria seca dos frutos $(20,55 \mathrm{~g}$ por planta) fosse obtido com o uso dos maiores níveis de nitrogênio e potássio na solução do solo (336 e $84 \mathrm{mg} \mathrm{L}^{-1}$, respectivamente) (Tabela 6).

A matéria seca total da parte aérea aumentou de forma quadrática com o aumento do nitrogênio e do potássio na solução do solo; entretanto, a interação significativa fez com que o valor máximo $(71,14 \mathrm{~g}$ por planta) fosse obtido com a manutenção de $336 \mathrm{mg} \mathrm{L}^{-1}$ de nitrogênio e $52 \mathrm{mg} \mathrm{L}^{-1}$ de potássio na solução do solo (Tabela 6).

Para o melão Gold mine cultivado em condições de campo com águas salinas, encontrou-se uma fitomassa seca de 37,66 g por planta no final do ciclo de cultivo, que se deu aos 62 dias após o plantio (Farias et al., 2003).

Comparando estes resultados, observa-se que a matéria seca acumulada em todas as partes da planta, neste estudo, foi inferior; entretanto, referido resultado seria previsível quando se considera que, em vasos, as condições de desenvolvimento da cultura são mais limitadas que em campo.

\section{CONCLUSÕES}

1. Para a maioria dos parâmetros vegetativos estudados na primeira planta, as maiores concentrações de nitrogênio (336 mg L $\left.{ }^{-1}\right)$ e de potássio $\left(84 \mathrm{mg} \mathrm{L}^{-1}\right)$ na solução do solo fizeram com que as funções ajustadas assumissem valores máximos.

2. No final do ciclo de cultivo a concentração de nitrogênio na solução do solo que propiciou os maiores valores para as funções ajustadas, foi de $336 \mathrm{mg} \mathrm{L}^{-1}$, e a de potássio variou desde a concentração natural (não aplicação de fertilizantes) até $84 \mathrm{mg} \mathrm{L}^{-1}$, tendo maior frequência entre 35 e $44 \mathrm{mg} \mathrm{L}^{-1}$.

\section{AGRADECIMENTOS}

Ao Conselho Nacional de Desenvolvimento Científico e Tecnológico - CNPq, pela concessão de auxílio financeiro para a realização da pesquisa, e à Universidade Federal Rural do Semiárido - UFERSA, pela concessão da infraestrutura.

\section{LITERATURA CITADA}

Alvarez, V. H. Avaliação da fertilidade do solo: Superfícies de resposta, modelos aproximativos para expressar a relação fator-resposta. Viçosa: UFV, 1994. 75p.

Bar-Yosef, B. Advances in fertigation. Advances in Agronomy, v.65, p.1-77, 1999.

Blanco, F. F.; Folegatti, M. V.; Henriques Neto, D. Doses de N e $\mathrm{K}$ no tomateiro sob estresse salino: I. Concentração de nutrientes no solo e na planta. Revista Brasileira de Engenharia Agrícola e Ambiental, v.12, n.1, p.26-33, 2008.

Castellane, P. D.; Araújo, J. A. C. Cultivo sem solo: Hidroponia. Jaboticabal: FUNEP, 1994. 43p.

Dias, N. de S.; Duarte, S. N.; Medeiros, J. F. de; Telles Filho, J. F. Salinidade e manejo da fertirrigação em ambiente protegido. I: Efeitos sobre o crescimento do meloeiro. Irriga, v.11, n.2, p.208-218, 2006.

Dias, N. deS.; Duarte, S. N.; Silva, E. F. F.; Folegatti, M. V. Manejo da Fertirrigação utilizando extratores de solução do solo. Piracicaba: ESALQ, 2004. 23p. Série Produtor Rural, 25

Farias, C. H. A.; Espínola Sobrinho, J.; Medeiros, J. F. de; Costa, M. C.; Nascimento, I. B.; Silva, M. C. C. Crescimento e desenvolvimento da cultura do melão sob diferentes lâminas de irrigação e salinidade da água. Revista Brasileira de Engenharia Agrícola e Ambiental, v.7, n.3, p.445-450, 2003.

Jiménez, S.; Alés, J. I.; Lao, M. T.; Plaza, B.; Pérez, M. Evaluation of nitrate quick tests to improve fertigation management. Communications in Soil Science and Plant Analysis, v.37, p.2461-2469, 2006.

Lao, M. T.; Jiménez, S.; Eymar, E.; Fernández, E. J. Nutrient levels of the solution obtained by means of suction cups in intensive tomato cultivation. Phyton, v.4, n.7, p.29-37, 2004.

Lao, M. T.; Jiménez, S.; Eymar, E.; Fernández, E. J.; Jiménez, R. Determination of spatial variability of nutrient composition of soil solutions in greenhouses by using suction cups. Communications in Soil Science and Plant Analysis, v.34, n. 5/6, p. 865-879, 2003.

Monteiro, R. O. C.; Coelho, R. D.; Melo, P. C. T.; Ferraz, P.; Chaves, S. W. P.; Shirahige, F.H.; Beltrame Neto, E.; Piedade, S.M.S. Net melon performance as affected by the drip irrigation depth and mulching. Horticultura Brasileira, v.26, p.447-451, 2008.

Rizzo, A. A. N.; Quijano, F. G.; Laura, V. A. Efeito da idade de mudas no desenvolvimento do melão rendilhado. Horticultura Brasileira, v.18, p.468-469, 2000.

Silva, E. F. F.; Anti, G. R.; Carmello, Q. A. C.; Duarte, S. N. Extratores de cápsulas porosas para o monitoramento da condutividade elétrica e do teor de potássio na solução de um solo. Scientia Agricola, v.57, n.4, p.785-789, 2000.

Vásquez, M. A. N. Fertirrigação por gotejamento superficial e subsuperficial no meloeiro (Cucumis melo L.) sob condições protegidas. Piracicaba: ESALQ, 2003. 145p. Tese Doutorado 